\title{
Ко-наем как стратегия выхода \\ из высокотехнологичных \\ инновационных компаний
}

\author{
Рамиль Рафиг-оглы Гасанов \\ Аспирант, старший инженер по техническому маркетингу \\ ORCID \\ E-mail: gasanoff.ramil@gmail.com
}

ООО «КАДЭКС», Нижний Новгород, Россия

Journal of Corporate Finance Research, Vol. 13, No. 2, pp. 114-125 (2019)

DOI: https://doi.org/10.17323/j.jcfr.2073-0438.13.2.2019.114-125

Поступила в редакцию 27 марта 2019 | Получена рецензия 20 апреля 2019 |

Принята к публикации 3 июня 2019 


\section{Ко-наем как стратегия выхода из высокотехнологичных инновационных компаний}

\section{Аннотация}

Венчурный бизнес традиционно связан с высокой степенью риска. По оценке консалтинговых компаний, лишь $23 \%$ инвестиций окажутся коммерчески состоятельными. Это говорит о том, что большинство вложений не будут возвращены. Такие потери неприемлемы для стагнирующего отечественного рынка венчурных инвестиций, поэтому одна из ключевых задач, встающих перед инвесторами, - нахождение методов максимизации отдачи от неудачных инвестиций. Ко-наем может стать таким методом. Цель работы - проанализировать механизм ко-найма и рассмотреть его финансовую модель.

Для анализа механизма был использован кейсовый метод. В статье рассмотрена активность корпорации Facebook на рынке поглощений, выделены и проанализированы примеры, в которых поглощение носит характер ко-найма. Определены также предпосылки появления этого механизма, рассмотрены финансовая модель, методы оценки стартапа, изучена структура сделок.

В результате было выведено определение ко-найма, произведены анализ и описание механизма, определены текущие подходы к структурированию подобных сделок, описана финансовая модель и рассмотрены альтернативные подходы к финансированию механизма. Было обнаружено, что в настоящее время не существует устоявшихся практик по поглощению стартапов с целью найма. Сделки могут регулироваться договором об оказании услуг, договором о покупке исключительных прав на интеллектуальную собственность или покупке доли в стартапе. Финансовая модель включает два пула: пул «рассмотрения сделки» и компенсационный пул. Первый пул попадает в руки инвесторов и стейкхолдеров после ликвидации компании. Компенсационный пул состоит из денежных средств и опционов, которые предназначены для сотрудников, нанимаемых в корпорацию.

Научная новизна статьи заключается в том, что описываются специфические черты ко-найма, позволяющие классифицировать его как отдельный механизм выхода.

Описанный в статье механизм имеет практическую ценность для венчурных инвесторов, осуществивших инвестиции в проекты, темпы роста которых не удовлетворяют ожидаемым. Применение этого механизма на практике будет способствовать повышению рентабельности подобных инвестиций.

Ключевые слова: ко-наем, приобретение талантов, слияния и поглощения, венчурный капитал, стратегия выхода, инвестиции

JEL classification: G24, G34, L24 


\section{Введение}

Венчурные инвестиции связаны с высокой степенью неопределенности и риска. Из анализа СB insights, проведенного на выборке из 1027 технологических стартапов, которые получили посевные инвестиции в 2008-2010 гг., следует, что 48\%, или 489 компаний ликвидируются либо выходят на нулевую операционную рентабельность, не привлекая последующие раунды финансирования (рис. 1). Такие компании не приносят инвесторам дивидендов, а их потенциал роста сильно ограничен, что делает подобные инвестиции несостоятельными [1]. Всего из 1027 стартапов таких результатов достигла 791 компания, а это значит, что 77\% посевных инвестиций оказались несостоятельными (см. рис. 1).

В 2016 г. в России было осуществлено венчурных инвестиций на сумму 507 млн долл. [2, с. 24]. Исходя из мировой практики, лишь 23\% этих средств принесут прибыль. Для стагнирующего отечественного рынка венчурных инвестиций такие потери неприемлемы, и одна из важнейших задач, встающих перед инвесторами, - коммерциализация проваленных проектов.

Естественным способом защиты инвестиций является выход из неблагоприятного актива. Однако каким образом можно выйти из неудачного проекта? Кто и на каких условиях согласится выкупить долю инвестора в компании, которая за время своего существования не смогла найти свою целевую аудиторию, определить рынок и продвинуть на него свой продукт?

\section{Погоня за талантами}

У большинства стартапов есть то, что жизненно необходимо стратегическим партнерам, а именно - компетенции. Как отмечают исследователи [3], одним из ключевых критериев осуществления венчурных инвестиций является команда. Технологические гиганты испытывают постоянный кадровый голод, который в последнее десятилетие так и не был удовлетворен. Поэтому, когда стартап оказывается в плачевном финансовом состоянии, вместо ликвидации имеет смысл попытаться продать накопленные компетенции заинтересованной корпорации.

История Силиконовой долины и других инновационных кластеров по всему миру неразрывно связана с постоянно растущим кадровым голодом. Спрос на разработчиков программного обеспечения временно утих после того, как лопнул «пузырь дот-комов», но спустя десятилетие вновь достиг своего апогея вместе с уверенным ростом западного рынка венчурного капитала. Сегодня технологические гиганты готовы предложить привлекательные бонусы для привлечения и удержания талантливых инженеров. Они могут включать высокую фиксированную плату, выгодные опционы, прозрачные условия движения по карьерной лестнице, комфортабельные офисы, передовое оборудование, медицинское страхование для сотрудников и их семей.

Однако, несмотря на все преимущества работы на корпорацию, многие инженеры предпочитают запустить стартап самостоятельно или присоединиться к начинающей команде. Такие люди согласны на менее привлекательные зарплаты и отсутствие разнообразных бонусов, взамен они получают более полный контроль над будущим проекта и в случае, если стартап окажется успешным, возможность получить состояние при выходе из проекта. Кроме того, предпринимательство дает убедительные имиджевые преимущества, одобряется бизнес-сообществом и обществом в целом [4, с. 13].

В последнее время участие в стартапе становится все более привлекательным вследствие трех убедительных мотиваторов.

Стоимость основания инновационной компании существенно снизилась за счет множества государственных программ субсидирования и поддержки малого предпринимательства.

Рисунок 1. Воронка венчурного капитала

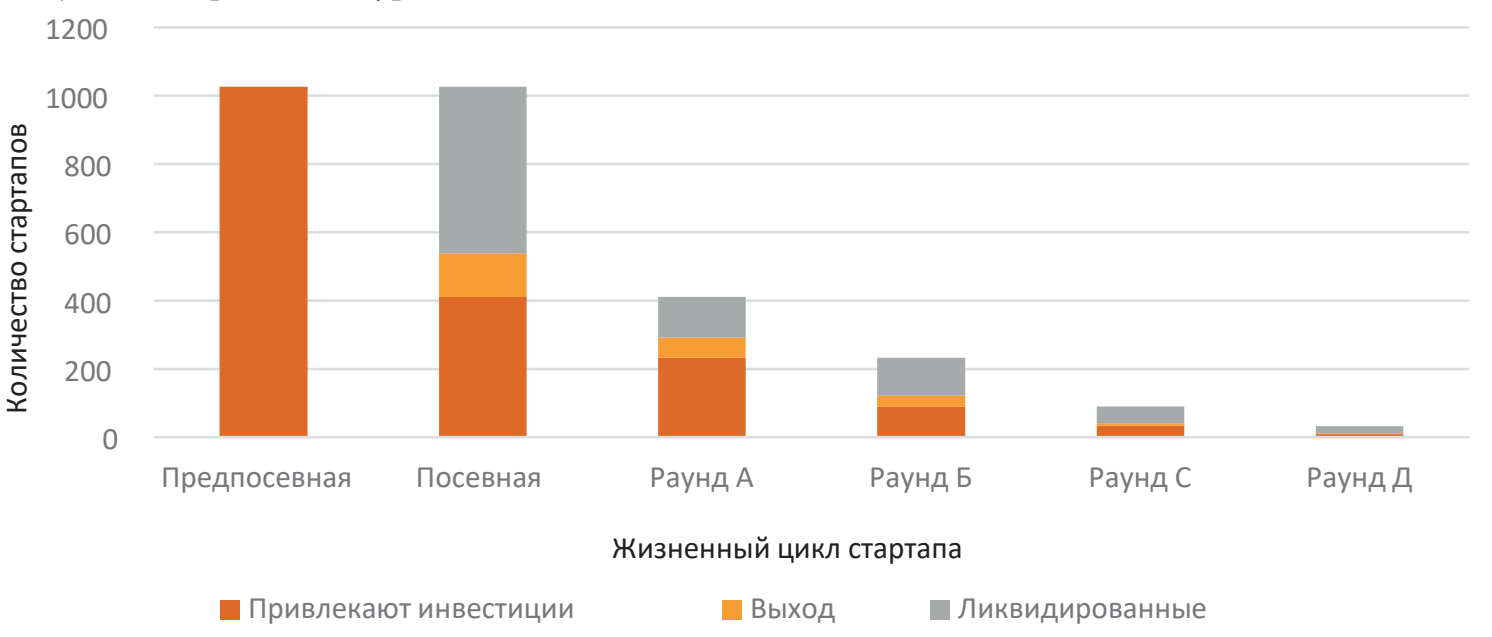

Источник: [1]. 
В дополнение к этому доступ к облачным технологиям и гранты от крупных инфраструктурных провайдеров (Microsoft, Amazon Web Services) позволяют практически полностью сократить расходы на серверное оборудование и лицензии на необходимое программное обеспечение. Например, программа Microsoft for Startups предлагает более 120 тыс. долл. в виде гранта на вычислительные мощности, ПО для разработки и офисное ПО [6].

Сегодня венчурное финансирование стало как никогда доступным. Отечественные и зарубежные венчурные инвесторы, бизнес-ангелы, акселераторы финансируют проекты даже на самых ранних стадиях.

Наличие доступа к венчурным деньгам в совокупности со снижением стоимости открытия бизнеса позволяет основателям предлагать более конкурентоспособную оплату труда и опционные программы. Скорость роста стартапов многократно превышает скорость роста крупных компаний, соответственно ценность доли в подобных проектах также стремительно растет.

В совокупности эти факторы говорят о том, что сегодня найти финансирование, привлечь в команду талантливых разработчиков и запустить инновационное предприятие легче, чем когда-либо. В свете этих обстоятельств конкуренция за талантливых разработчиков в последнее десятилетие только растет.

\section{Ко-наем}

При классических слияниях и поглощениях главная цель покупателя - получение права собственности на материальные (недвижимость, оборудование, транспорт) и нематериальные (интеллектуальная собственность, аудитория, бренд) активы компании. При ко-найме покупающая компания, как правило, не заинтересована в операционной деятельности цели или приобретении ее активов, основную ценность представляет команда профессионалов.

Например, команда сервиса Drop.iо присоединилась к Facebook 29 октября 2010 г. На момент приобретения стартап существовал три года и привлек 8,80 млн долл. в трех раундах финансирования. Drop.io был основан Сэмом Лессином [7], его сервис позволял пользователям обмениваться фотографиями, видеозаписями и другими файлами онлайн. В своей записи, посвященной сделке, основатель объявил о том, что продукт компании будет закрыт, а данные пользователей будут удалены, несмотря на то, что многие пользователи платили за использование сервиса. Из той же записи следует, что Facebook приобрел «большинство технологий». Это говорит о том, что не все наработки Drop.io интересовали Facebook. B peзультате команда сервиса во главе с Сэмом Лессином присоединилась к крупнейшей социальной сети [7].

Другое показательное приобретение Facebook - cтартап FriendFeed. Пресс-релиз корпорации от 10 августа
2009 г. гласит: «Facebook сегодня анонсирует поглощение FriendFeed - инновационного онлайн-сервиса для публикации пользовательских новостей. В рамках соглашения все сотрудники FriendFeed присоединятся к Facebook вместе с четырьмя основателями, которые займут руководящие позиции в инженерных и продуктовых командах». В течение нескольких лет продукт FriendFeed поддерживался уже силами корпорации до того, как был полностью закрыт [8].

Как видно из приведенных примеров, в обоих случаях корпорации был важен доступ к команде и их компетенциям, а не финансовая составляющая этих проектов.

Одним из самых ярких примеров ко-найма на рынке СНГ является поглощение белорусской Masquerade Technologies социальной сетью Facebook 9 марта 2016 г. [9].

Продуктом Masquerade Technologies является мобильное приложение MSQRD [10], которое распознает лица людей в видеопотоке и накладывает на них «маски». По словам основателей компании, подобная идея родилась на волне популярности таких приложений, как Periscope и Snapchat.

Процессы распознавания лиц и замены изображения в реальном времени достаточно ресурсоемкие, поэтому краеугольными камнями являлись производительность приложения и способность работать на смартфонах с низкими техническими характеристиками. Благодаря опыту основателей в сфере разработки компьютерных игр им удалось достичь достаточно высокой скорости обработки видеопотока, таким образом обеспечив замену лиц в реальном времени. Основатель компании Евгений Невгень отметил: «Нам удалось сжать модель данных, используемую трекингом, со 120 МБ до 12,4 МБ при потере качества всего в 3-5\%». Благодаря продуманной технологии MSQRD быстро работает и на новых, и на старых смартфонах. Обладая устойчивым, технологически сложным продуктом, компания привлекла 1 млн долл. инвестиций от российских инвесторов. На фоне роста популярности белорусского приложения к компании стал возникать интерес со стороны технологических гигантов, которые охотились за необходимыми компетенциями. Одним из таких гигантов был Facebook, который и приобрел команду проекта.

В процессе интеграции команда Masquerade Technologies начала работу над приложением Instagram, обогащая его функционалом, при этом последнее обновление их собственного приложения MSQRD произошло 2 августа 2016 г. [10]. Это говорит о том, что корпорация Facebook не была заинтересована в развитии продукта Masquerade Technologies или ее дальнейшей операционной деятельности. Наиболее важными активами являлись команда и ее наработки в области видеостриминга, отслеживания лица и 3D-плейсмента. Кривая обучаемости для этих навыков необычайно крута, а соответствующие специалисты весьма редкие. 
Рисунок 2. Рост стоимости акций Facebook во время приобретения Masquerade Technologies

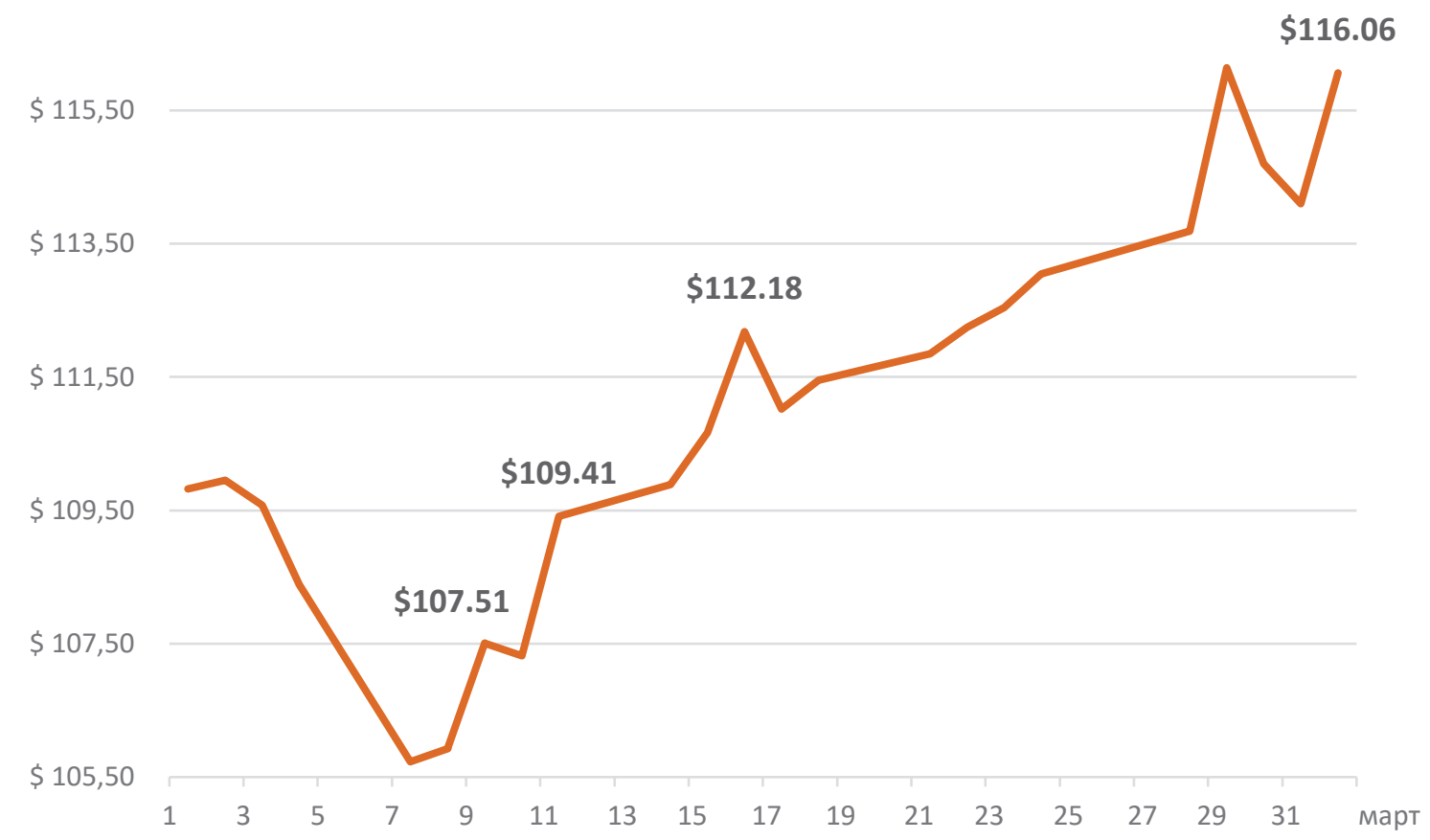

Источник: [12].

Рисунок 3. Количество людей, присоединившихся к Facebook в результате поглощений

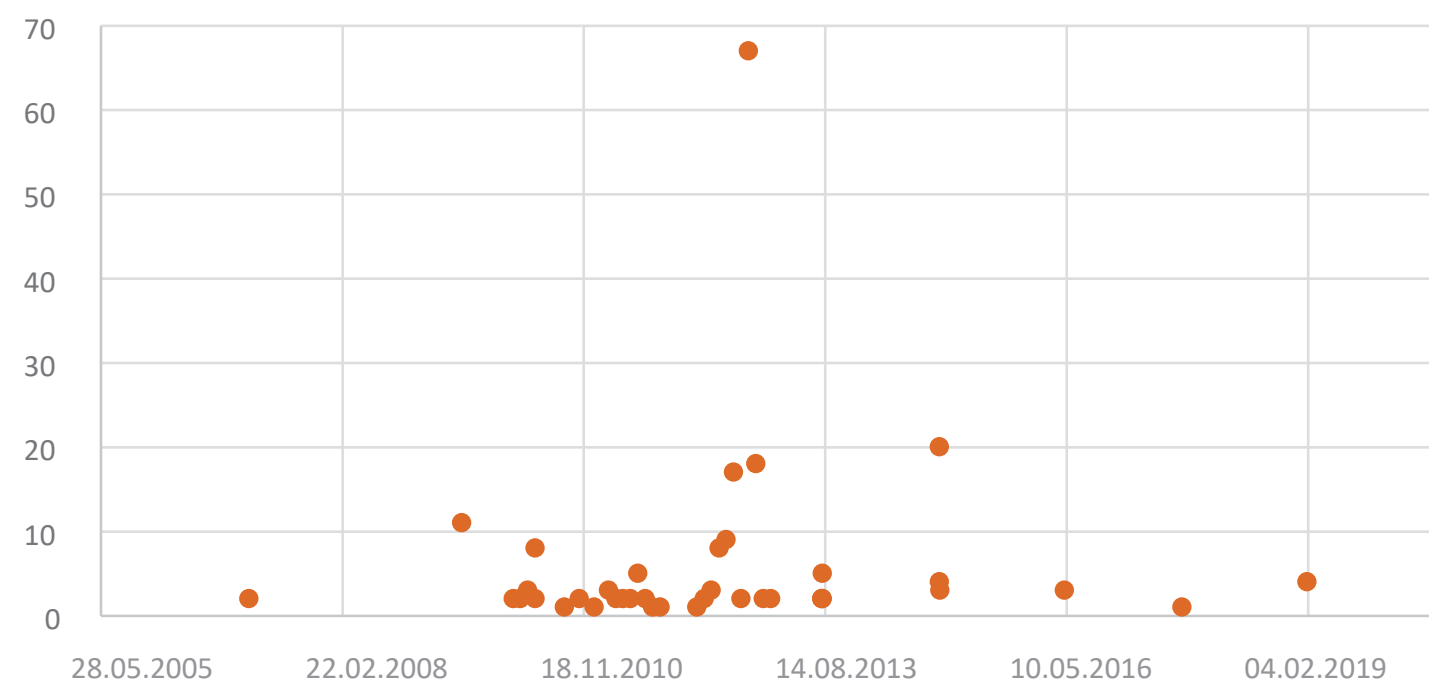

Источник: [13].

Стратегической целью социальной сети, купившей белорусский стартап, было привлечение поколения миллениалов, среди которых сервисы с подобным функционалом имеют высокую популярность. Монополистом на рынке видеофильтров было приложение Snapchat, которое Facebook неудачно пытался приобрести в 2013 г. [11]. Ко-наем Masquerade Technologies позволил быстро получить необходимые компетенции и усилить конкурентную позицию Facebook на стратегически важном рынке.

На момент приобретения Masquerade Technologies акции Facebook котировались по цене 107,51 долл. Спустя два дня акции выросли в цене на 1,77\% и достигли
109,41 долл. Спустя неделю динамика увеличилась, и стоимость акций составила 112,18 долл. К концу месяца стоимость акций достигла 116,0 долл. Таким образом, капитализация компании увеличилась на $8,55 \%$ за 22 дня и в денежном выражении составила 339,01 млрд долл., что на 26,69 млрд долл. выше ее стоимости до покупки MSQRD (см. рис. 2). Очевидно, что усиление конкурентной позиции на рынке видеофильтров значительно сказалось на инвестиционной привлекательности Facebook.

Корпорация Facebook - одна из самых активных на рынке M\&A. По данным Crunchbase, с 2007 г. технологический гигант приобрел 63 стартапа, наняв при 
этом более 200 человек из 40 компаний. Это говорит о том, что в $63,49 \%$ случаев приобретение талантов выступило основным драйвером для сделки. На рис. 3 отражено количество людей, присоединившихся к Facebook в результате присоединения их работодателя к корпорации. Из рисунка видно, что, как правило, корпорация приобретает небольшие команды размером до 10 человек, при этом основная активность приходится на 2009-2013 гг.

Технологические гиганты покупают молодые компании с тем, чтобы вовлечь их в свои собственные проекты. Такой подход дает корпорациям возможность минимизации стоимости сделки за счет отказа от покупки всей накопленной интеллектуальной собственности и других, менее важных активов. Нанять слаженную команду с доказанным опытом создания продуктов куда проще и надежнее, нежели собирать такую же команду с нуля. Таким образом, можно предложить следующее определение ко-найму.

Ко-наем - процесс приобретения компании с целью найма ее персонала, при этом остальные материальные и нематериальные активы поглощаемой компании имеют второстепенное значение для покупающей компании.

Ко-наем может произойти на любой жизненной стадии компании, но чаще всего сделки заключаются между посевной стадией и стадией роста. Так произошло и с компанией Masquerade Technologies. Она была приобретена после раунда посевных инвестиций и до активного экономического роста. Как правило, на этом этапе основатели осознают, что стартап, скорее всего, не сможет вывести продукт на рынок и занять свою нишу. Таким образом, перед основателями встает вопрос о дальнейшей судьбе компании. Среди вариантов его решения: привлечение дополнительных инвестиций (что ведет к размыванию доли и не гарантирует дальнейшего успеха), ликвидация или ко-наем.

Джон Койл и Грег Польский [14] в своем исследовании проводят интервью среди предпринимателей и инвесторов Силиконовой долины, которые подтверждают, что ко-наем в большинстве случаев происходит именно по такому сценарию. В других случаях ко-наем был проведен вместо последующих раундов финансирования, так как условия привлечения нового раунда инвестиций не устраивали основателей.

Респонденты того же исследования подчеркивают, что на данный момент не выработано каких-либо стандартов или устоявшихся практик. Структура сделок сильно разнится от случая к случаю. Например, компания из трех-пяти человек может быть куплена за сумму менее 500 тыс. долл. При таком сценарии трансакция может регулироваться обычным договором об оказании услуг, в рамках которого компания получает денежный транш за определенные услуги. После выполнения договора стартап ликвидируется, a ее сотрудники в рамках стандартного трудового договора нанимаются в покупающую компанию. Очевидно, что такие условия не могут устояться в качестве практики, так как покупающая компания не может обязать сотрудников покупаемой компании трудоустроиться в нее. Это может привести к частичному или полному отказу штата «переселиться» в новую компанию.

В более крупных трансакциях принято структурировать сделку в соответствии с требованиями о покупке собственности. Как правило, при таком подходе имеется в виду покупка исключительного права гражданина или юридического лица на результаты интеллектуальной деятельности. Другая собственность (недвижимость, оборудование, транспорт) зачастую не участвует в сделке. Денежные средства (или опционы), уплаченные покупателем, распределяются между основателями и инвесторами поглощаемой компании в порядке приоритетов в процессе ликвидации компании.

\section{Оценка стартапа \\ и структурирование сделки}

При определении цены стартап, как правило, оценивается по количеству сотрудников. Однако вопрос цены остается крайне вариативным. По данным юристов по сопровождению слияний и поглощений из Lowenstein Sandler [15], существует негласное правило, по которому каждый разработчик оценивается в 1 млн долл. На практике конечный объем сделки варьируется от 200-300 тыс. до 50 млн долл. и более.

Несмотря на все разнообразие, во всех осуществленных сделках наблюдалась общая черта: выплаты, состоящие из денежных средств и опционов, делились на два пула.

Первый пул Джон Койл и Грег Польски [14, с. 19] назвали “deal consideration” («рассмотрение сделки»), он направлялся на приобретение стартапа. В зависимости от структуры сделки этот пул использовался для оплаты услуг инженеров, покупки интеллектуальной собственности (либо любой другой собственности) или доли в компании. Пул рассмотрения сделки во время ликвидации компании окажется у стейкхолдеров стартапа. Ими могут быть как ее основатели, так и внешние инвесторы.

Второй пул, называемый “compensation pool” («компенсационный пул»), использовался для вознаграждения сотрудников, которые впоследствии перейдут на работу в компанию-приобретателя. Как правило, большая часть пула представляет собой опционы, предоставляемые сотрудникам на определенных условиях. Практически во всех исследуемых случаях опционы были привязаны к сроку, в течение которого обязан проработать сотрудник (в среднем три-четыре года). 
Причем опционы традиционно сопровождаются годовым порогом, или клиффом. Годовой порог говорит о том, что работник не сможет реализовать свой опцион до тех пор, пока не проработает год в покупающей компании. После годового порога части опциона будут доступны сотруднику пропорционально отработанному сроку. Рассмотрим пример, когда по условиям договора сотрудник должен отработать четыре года чтобы полностью реализовать свой опцион, а клифф составляет один год. Это означает, что после одного года работы сотрудник может реализовать $25 \%$ опциона, а оставшаяся часть будет поступать пропорционально в течение оставшихся трех лет на ежемесячной основе.

Помимо срока работы опционы могут быть привязаны к определенным ключевым показателям эффективности. Например, при разработке ПО могут быть использованы следующие показатели: количество релизов новых версий продукта, количество выявленных уязвимостей или ошибок.

Важный аспект компенсационного пула заключается в том, что он предоставляется исключительно тем сотрудникам, которые будут трудоустроены в покупающую корпорацию. Другими словами, ни инвесторы, ни стейкхолдеры (отказавшиеся от нового места работы) не получают из него никаких выгод.

На практике компенсационный пул практически полностью направляется рядовым сотрудникам, так как наибольший интерес для покупателя представляет команда инженеров-разработчиков.

Таким образом, денежные средства и опционы, получаемые поглощаемой компанией, делятся на два пула. Из-за наличия такой структуры сделки ключевым вопросом становится распределение общих выплат на два пула. Здесь возникает очевидный конфликт интересов. Инвесторы и стейкхолдеры (не нанимаемые в новую компанию) предпочли бы аллокацию ресурсов в направлении пула «рассмотрение сделки». С другой стороны, инженеры и стейкхолдеры (нанимаемые в корпорацию) будут заинтересованы в распределении общей суммы в сторону компенсационного пула.

Покупающая компания также заинтересована в увеличении компенсационного пула, так как от его размера и условий выплат будет зависеть мотивация ее будущих сотрудников. При ко-найме основным (если не единственным) мотивом покупателя являются привлечение и удержание команды. Если компенсационные пакеты не будут устраивать инженеров, и они покинут компанию через один-два года, то смысл приобретения будет стремиться к «нулю». Получается, что с точки зрения покупателя первый пул является издержками, необходимыми для проведения сделки.

Таким образом, при распределении ресурсов интересы покупателя и инженерной команды противопоставляются интересам стейкхолдеров и инвесторов. Профессиональное мнение относительно распределе- ния бюджета делится на два лагеря. Инвесторы считают, что пул «рассмотрения сделки» должен удовлетворять прежде всего их интересам, так как если бы они не профинансировали посевной раунд, то у стартапа не было бы возможности собрать талантливую команду, доказать ее жизнеспособность и получить предложение от покупателя. С другой стороны, наибольшую ценность представляет именно человеческий капитал - инженеры, на которых у инвесторов не может быть никаких юридически обоснованных рычагов давления. Поэтому, по мнению сотрудников стартапов, большинство средств должно быть направлено именно в компенсационный пул. Кроме того, альтернативой ко-найма является ликвидация, при которой инвесторы в лучшем случае вернут ничтожную часть своих инвестиций.

Основная функция пула "рассмотрение сделки» выплата инвесторам минимально возможной суммы, позволяющей, во-первых, удовлетворить их потребности, во-вторых, сохранить хорошие отношения между стейкхолдерами (которые в будущем, возможно, захотят основать новую компанию) и инвесторами. Потребности инвесторов и хорошие отношения стейкхолдеров тяжело перевести в денежный эквивалент, поэтому оценка пула «рассмотрение сделки» может быть крайне проблематичной. Ведь если инженерная команда почувствует риск занижения их «стоимости», то они могут попросту уволиться и перейти в корпорацию, при этом ничего не потеряв, а инвесторы и стейкхолдеры останутся ни с чем. В таком случае необходимо найти правильный баланс между интересами инвесторов, стейкхолдеров и рядовых разработчиков. Но как его найти? Сколько должен получить инвестор? Какова адекватная цена для разработчика? Практика показывает, что для выяснения этих вопросов требуется колоссальное количество времени и переговоров. Кроме того, увеличение вариативности возможных результатов неизбежно приводит к неопределенности, которая может повлечь нежелательные риски в будущем. Поэтому респонденты, интервьюируемые Джоном Койлом и Грегом Польски [14], на вопрос о размере выплат отвечают, что на рынке, скорее всего, устоится один из двух подходов, по которым инвестор получает либо фиксированный процент, например 15-20\% от общего размера выплат, либо выплату в размере изначальных вложений. Это во многом ускорило бы процессы принятия решений в вопросах ко-найма и сократило бы неопределенность.

Так или иначе, основным подходом может остаться практика выплаты инвесторам изначальных вложений вследствие трех аргументов.

Инвесторы привыкли брать свои изначальные вложения за точку старта. Вкладывая в стартап, они ожидают вернуть вложения в десяти- или тридцатикратном размере, при этом именно изначальные вложения служат основным ориентиром [16]. 
Аллокация финансов на основе фиксированного процента вызовет ряд практических проблем. Из-за того, что инвесторы не имеют отношения к компенсационному пулу, они могут быть не осведомлены о его размере и деталях выплаты. Поэтому для вычисления корректной доли инвесторы должны быть проинформированы о деталях выплат инженерам, что не всегда может быть комфортно для команды стартапа. Кроме того, даже если инвестор будет в курсе всех деталей, рассчитать корректную выплату будет проблематично, ведь большая часть компенсационного пула традиционно представляет собой опционы, привязанные к условленным КПЭ (ключевые показатели эффективности). Один из базовых КПЭ - время работы на покупающую корпорацию. Таким образом, даже если применять принцип дисконтирования, необходимо учитывать риск неисполнения инженерами обязательств, который тяжело вычислить.

Многие основатели стартапов руководствуются благородным мотивом - вернуть вложенные средства инвесторов. Это позволяет не только улучшать бизнес-климат в России, но и сохраняет востребованные контакты для финансирования новых предприятий в будущем.

Таким образом, использование вложенных инвестором средств в качестве точки отсчета послужит удобным и предсказуемым ориентиром. Кроме того, если оценивать пул «рассмотрение сделки» на основе процентов владения компанией, то конечный размер выплаты инвесторам во многом зависел бы от правил распределения ресурсов при ликвидации юридического лица и стоимости компании, которая может быть низкой на фоне экономических провалов стартапа. Это говорит о том, что в ряде случаев фиксированная выплата в размере изначальных вложений будет выше, чем фиксированный процент от суммы выплат.

Это дает нам право предполагать, что в будущем при ко-найме устоится практика возврата инвесторам вложенных средств, и это поможет решить проблемы, связанные с аллокацией ресурсов между компенсационным пулом и пулом «рассмотрение сделки».

\section{Заключение}

В статье мы рассмотрели предпосылки появления механизма ко-найма, привели практический пример, проанализировали феномен ко-найма и выяснили, что в настоящее время не существует устоявшихся практик по поглощению стартапов с целью найма персонала. От случая к случаю сделки регулируются договором об оказании услуг, договором о покупке исключительных прав на интеллектуальную собственность или покупке доли в стартапе.

Однако в транзакциях ко-найма наблюдаются общие черты. Конечная цена поглощаемого актива зависит от количества сотрудников стартапа. Финансовая модель включает два пула: пул «рассмотрения сделки» и компенсационный пул. Первый пул попадает в руки инвесторов и стейкхолдеров после ликвидации компании. Компенсационный пул состоит из денежных средств и опционов, которые предназначены для сотрудников, нанимаемых в корпорацию.

В условиях стагнирующего рынка венчурных инвестиций и неблагоприятной макроэкономической ситуации в целом крайне важно определить работающие механизмы защиты инвестиций. Ко-наем, как механизм выхода из неблагоприятных активов, может помочь сократить издержки и обеспечить инвесторов денежными средствами для финансирования новых проектов. В качестве темы для будущих исследований можно рассмотреть долгосрочное влияние ко-найма на покупающую корпорацию.

\section{Список литературы}

1. Venture capital funnel shows odds of becoming a unicorn are about 1\%. CB Insights. 2018. URL: https://www.cbinsights.com/research/venture-capitalfunnel-2/

2. Обзор рынка. Прямые и венчурные инвестиции в России: 2016 год. СПб.: Российская Ассоциация Венчурных Инвестиций; 2017. 99 с. URL: http:// www.rvca.ru/rus/resource/library/rvca-yearbook/

3. Каширин А.И., Семенов А.С. Инновационный бизнес: венчурное и бизнес-ангельское инвестирование. М.: Дело; 2010. 258 с.

4. Обзор рынка. Прямые и венчурные инвестиции в России: 2015. СПб.: Российская Ассоциация Венчурных Инвестиций; 2016. 125 c. URL: http://www. rvca.ru/rus/resource/library/rvca-yearbook/

5. Механизмы стимулирования (налоговые и иные аспекты) при прямом и венчурном инвестировании. Возможности и перспективы, правоприменение, обоснованные предложения. М.: Российская венчурная компания; 2015. 87 c. URL: https:// www.rvc.ru/upload/iblock/eda/201512_incentive_ mechanisms_for_Venture_Capital.pdf

6. Майкрософт для стартапов. Microsoft. 2018. URL: https://startups.microsoft.com/ru-ru/

7. Lessin S. Drop.io to be acquired by Facebook Inc. 2010. URL: https://drop.io/news

8. Facebook agrees to acquire sharing service FriendFeed. Facebook. 2009. URL: https://newsroom. fb.com/news/2009/08/facebook-agrees-to-acquiresharing-service-friendfeed/

9. Lunden I. Facebook acquires video filter app MSQRD to square up to Snapchat. TechCrunch Inc. 2016. URL: https://techcrunch.com/2016/03/09/facebookacquires-video-filter-app-msqrd-to-square-up-tosnapchat 
10. MSQRD. Play Маркет. Google Play. 2016. URL: https://play.google.com/store/apps/details?id=me. msqrd.android\&hl $=\mathrm{ru}$

11. Bercovici J. Facebook tried to buy Snapchat for $\$ 3 B$ in cash. Here's why. Forbes. 2013. URL: https://www. forbes.com/sites/jeffbercovici/2013/11/13/facebookwouldve-bought-snapchat-for-3-billion-in-cashheres-why/\#5830d243dea8

12. Facebook, Inc. Class A common stock (FB) quote \& summary data. Nasdaq. 2019. URL: https://www. nasdaq.com/symbol/fb

13. Facebook. Overview: Number of acquisitions. Crunchbase. 2019. URL: https://www.crunchbase. com/organization/facebook\#section-overview

14. Coyle J.F, Polsky G.D. Acqui-hiring. Duke Law Journal. 2013;63(2):281-346. URL: https:// scholarship.law.duke.edu/cgi/viewcontent.cgi?referer $=\&$ httpsredir $=1 \&$ article $=3400 \&$ context $=\mathrm{dlj}$

15. Makinen M., Haber D., Raymundo A.W. Acquihires for growth: Planning for success. Venture Capital Review. 2012;(28):31-42. URL: https://www. lowenstein.com/media/4480/ey-venture_capital_ review.pdf

16. Festel G, Wuermseher M, Cattaneo G. Valuation of Early Stage High-tech start-up companies. International Journal of Business. 2013;18(3):216231. URL: https://pdfs.semanticscholar.org/e045/b33 3abafeb04455fb91f0fc1d305fedcb02f.pdf 


\section{Acqui-hire as an Exit Strategy from High-Tech Innovative Companies}

\section{Ramil Gasanov}

PhD student, Senior Technical Marketing Engineer

ORCID

E-mail: gasanoff.ramil@gmail.com

CADEX Ltd., Nizhny Novgorod, Russia

Journal of Corporate Finance Research, Vol. 13, No. 2, pp. 115-125 (2019)

DOI: https://doi.org/10.17323/j.jcfr.2073-0438.13.2.2019.115-125

Received 27 March 2019 | Peer-reviewed 20 April 2019 | Accepted 3 June 2019 


\section{Acqui-hire as an Exit Strategy from High-Tech Innovative Companies}

\section{Abstract}

Traditional venture investments are associated with a high degree of risk. According to industry consultants, only $23 \%$ of investments are commercially viable, which means that most investments will not see returns. Such losses are unacceptable in the stagnating Russian venture market. Therefore, a key goal of investors is to find methods for maximising returns on failed investments. 'Acqui-hire', or the acquisition of companies in order to recruit from their pool of talented employees, can become such a method.

This paper aims to describe the acqui-hire mechanism and analyse its financial model. Presented herein is a case study method which examines Facebook's activity on the M\&A market. As part of this evaluation, we will identify specific cases where acquisitions display relevant characteristics of the acqui-hire model. Common motivations behind acquihire are also discussed, the financial models which apply to the process are described, and startup valuation methods and typical deal structures associated with this mechanism are investigated.

As a result of this examination, we can assert that while distinct characteristics of acqui-hire may be identified, there is currently no broadly-established standard approach to acqui-hire activities. Individual deals may be structured in the form of service agreements, purchases of intellectual property, or equity acquisitions. We can identify that the relevant financial models comprise two general categories: the 'deal consideration' pool and the 'compensation' pool. The first pool relates primarily to investors and stakeholders, and concerns funds that are distributed after company liquidation. The second pool consists of options and funds that are dedicated to the employees who are going to join the acquiring corporation

The scientific novelty of this particular investigation consists in the descriptive breakdown of the specifics of acqui-hire, which allow for distinguishing it as a separate and distinct exit mechanism within the corporate milieu. As described herein, acqui-hire has practical value for venture investors in projects where growth rates do not meet expectations. Putting this mechanism into practice can certainly help to shore up the profitability of such investments.

Keywords: Acquihiring, M\&A, venture capital, exit strategy, investments, talent acquisition JEL classification: G24, G34, L24 


\section{References}

1. Venture capital funnel shows odds of becoming a unicorn are about 1\%. CB Insights. 2018. URL: https://www.cbinsights.com/research/venture-capitalfunnel-2/

2. Market review. Direct and venture capital investments in Russia: 2016. St. Petersburg: Russian Venture Capital Association; 2017. 99 p. URL: http:// www.rvca.ru/rus/resource/library/rvca-yearbook/ (In Russ.).

3. Kashirin A.I., Semenov A.S. Innovative business: Venture and angel investing. Moscow: Delo; 2010. 258 p. (In Russ.).

4. Market review. Direct and venture capital investments in Russia: 2015. St. Petersburg: Russian Venture Capital Association; 2016. 125 p. URL: http:// www.rvca.ru/rus/resource/library/rvca-yearbook/ (In Russ.).

5. Incentive mechanisms (tax and other aspects) for direct and venture investment. Opportunities and prospects, law enforcement, reasonable proposals. Moscow: Russian Venture Company; 2015. 87 p. (In Russ.).

6. Microsoft for startups. Microsoft. 2018. URL: https:// startups.microsoft.com/en-us/

7. Lessin S. Drop.io to be acquired by Facebook Inc. 2010. URL: https://drop.io/news

8. Facebook agrees to acquire sharing service FriendFeed. Facebook. 2009. URL: https://newsroom. fb.com/news/2009/08/facebook-agrees-to-acquiresharing-service-friendfeed/

9. Lunden I. Facebook acquires video filter app MSQRD to square up to Snapchat. TechCrunch Inc. 2016. URL: https://techcrunch.com/2016/03/09/facebookacquires-video-filter-app-msqrd-to-square-up-tosnapchat
10. MSQRD. Shop. Google Play. 2016. URL: https:// play.google.com/store/apps/details?id=me.msqrd. android\&hl=en

11. Bercovici J. Facebook tried to buy Snapchat for $\$ 3 B$ in cash. Here's why. Forbes. 2013. URL: https://www. forbes.com/sites/jeffbercovici/2013/11/13/facebookwouldve-bought-snapchat-for-3-billion-in-cashheres-why/\#5830d243dea 8

12. Facebook, Inc. Class A common stock (FB) quote \& summary data. Nasdaq. 2019. URL: https://www. nasdaq.com/symbol/fb

13. Facebook. Overview: Number of acquisitions. Crunchbase. 2019. URL: https://www.crunchbase. com/organization/facebook\#section-overview

14. Coyle J.F, Polsky G.D. Acqui-hiring. Duke Law Journal. 2013;63(2):281-346. URL: https:// scholarship.law.duke.edu/cgi/viewcontent.cgi?referer $=\&$ httpsredir $=1 \&$ article $=3400 \&$ context $=\mathrm{dlj}$

15. Makinen M., Haber D., Raymundo A.W. Acquihires for growth: Planning for success. Venture Capital Review. 2012;(28):31-42. URL: https://www. lowenstein.com/media/4480/ey-venture_capital_ review.pdf

16. Festel G, Wuermseher M, Cattaneo G. Valuation of Early Stage High-tech start-up companies. International Journal of Business. 2013;18(3):216231. URL: https://pdfs.semanticscholar.org/e045/b33 3abafeb04455fb91f0fc1d305fedcb02f.pdf 